\title{
Influence of Multiharmonics Excitation on Rattle Noise in Automotive Gearboxes
}

\author{
Y. Kadmiri, ${ }^{1,2}$ J. Perret-Liaudet, ${ }^{1}$ E. Rigaud, ${ }^{1}$ A. Le Bot, ${ }^{1}$ and L. Vary ${ }^{2}$ \\ ${ }^{1}$ Laboratoire de Tribologie et Dynamique des Systèmes, UMR CNRS 5513, Ecole Centrale de Lyon, Université de Lyon, \\ 69130 Ecully, France \\ ${ }^{2}$ Renault S.A.S., Centre Technique, 91510 Lardy, France
}

Correspondence should be addressed to Y. Kadmiri, younes.kadmiri@ec-lyon.fr

Received 12 January 2011; Accepted 2 June 2011

Academic Editor: Kok Keong Choong

Copyright (๑) 2011 Y. Kadmiri et al. This is an open access article distributed under the Creative Commons Attribution License, which permits unrestricted use, distribution, and reproduction in any medium, provided the original work is properly cited.

\begin{abstract}
We consider the automotive gearbox rattle noise resulting from vibro-impacts that can occur between the idle gears under excessive velocity fluctuations of the shaft-driving gears imposed by engine torque fluctuation. Even if the rattling phenomenon has no consequence on reliability, it may be particularly annoying for vehicle interior sound quality and acoustic comfort. The main parameters governing such kind of vibrations are the excitation source associated with engine torque fluctuation which can be modeled by an imposed displacement of the driveline, the inertia of the idle gear, the drag torque acting during the free flight motion, and the impact laws. In the case of rattle, it is reasonable to assume that duration of impacts between teeth is very short compared to the excitation period. Then, these impacts are modeled by a coefficient of restitution law. The excitation source is not composed only with fundamental component but also with other harmonic components. This study presents some effects of these additional components on the dynamic response of the idle gear.
\end{abstract}

\section{Introduction}

Acoustic comfort is an important sales point, in particular in car industry [1]. For many years, the research efforts allowed reduction of acoustic levels, in particular those related to interior sources like the engine-related noise and to exterior sources as tire and wind-related noises [2]. Consequently, noise sources that were previously masked emerge, because of the total reduction of the acoustic level. Among those, rattle noise in automotive gearboxes needs to be reduced. Actually, it is perceived like an unpleasant noise, more for its intrusive character, than for the acoustic levels generated.

Rattle noise results from the dynamic behavior of idle gears induced by the fluctuations of the driveline velocity. Under certain operating conditions, the idle gears can vibrate through their functional backlashes. Consequently, rattle noise is mainly related to impacts between gear teeth. The only harmful effect is radiated noise since impacts between gears do not change the dynamic behavior of the drivelines and do not lead to excessive loads and damage.
The key parameters governing rattle noise are the inertia of the idle gears, the drag torque acting on the idle gears, the elastic, and damping characteristics during impacts and free flights and the velocity fluctuations of the driving gears. These last ones result from velocity fluctuation of the engine which mainly depends on the engine type, driveline design, and car running conditions [3]. Frequency content is dominated by harmonics of the engine rotational velocity.

There are several studies concerning rattle noise [3-9]. Among these, some deal with the analysis of the complete dynamic behavior of the entire driveline in relation with design [4-6], whereas others remain localized on the idle gears dynamics $[7,8]$. Two ways are retained for introducing the impact force [10]: it is modeled by stereo-mechanical impact with the introduction of a coefficient of restitution [7, $8,11-13]$, or by elastic and damping characteristics during impacts [5]. Other authors concentrate their analysis on drag torque [14]. In all these studies, the excitation source is 
generally introduced as a purely harmonic excitation related to the engine torque fluctuations. Few experimental studies recently considered multiharmonic excitations $[13,15,16]$.

In this context, the main objective of this paper is to present some theoretical results in relation with the effects of multiharmonics excitation related to the acyclic fluctuations induced by engine torque.

\section{Assumptions}

Several assumptions for modeling the motion of the idle gear can be done as follows. Impacts duration is supposed infinitely short so that impacts are described by a coefficient of restitution. Drag torque is assumed to be constant during the gear-free flight. This assumption remains valuable as long as velocity fluctuation of the driving gear remains negligible compared with the average velocity. In addition, interactions between the dynamic response of the idle driven gear and the motion of the driving gear are neglected. The motion of the driving gear is assumed to be a periodic function and corresponds to the excitation source. Finally, backlash between teeth is assumed to be constant. Based on these assumptions, a single-degree-of-freedom nonlinear model is built to describe the idle gear dynamics.

\section{Dynamic Modeling}

3.1. Equation of Motion. The nonlinear single-degree-offreedom model of rattle gear is displayed in Figure 1. $x(t)$ is the equivalent displacement along the line of action corresponding to angular fluctuations of the idle gear around its theoretical position, $m$ is an equivalent mass associated with its inertia, $F$ is the constant force associated with the drag torque, $y(t)$ is the periodic displacement function taking into account the engine velocity fluctuation, and $j$ is the constant backlash between teeth. Equation of motion during the idle gear free flight can be written in the following form:

$$
m \ddot{x}=-F, \quad y(t)<x(t)<y(t)+j .
$$

A simple and usual law describing stereo-mechanical impact is introduced:

$$
\dot{x}_{t+\delta t}-\dot{y}_{t+\delta t}=-r\left(\dot{x}_{t}-\dot{y}_{t}\right) \text {, }
$$

with

$$
\delta t \longrightarrow 0
$$

where superdot denotes derivative respect to time and $r$ is the coefficient of restitution taking into account dissipation during impact.

In addition, a limit impact velocity is defined for which there are no rebounds anymore. Therefore, conditions leading to a permanent contact between driven and driving gears need to be expressed. Beyond this limit velocity, contact between gears is preserved as long as the reaction force acting
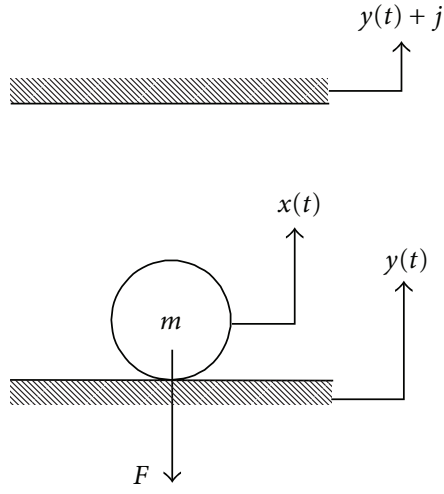

FIGURE 1: Rattle gear modeling.

on the free driven gear $R(t)$ remains positive. Thus, for the active flank, the following condition must be verified:

$$
0<R(t)=F+m \ddot{y}(t)
$$

and for the reverse flank,

$$
0>R(t)=F+m \ddot{y}(t) .
$$

Finally, the displacement excitation is described in the following subchapter.

3.2. Displacement Excitation. In the case of heat reciprocating engine, torque fluctuations are periodic and characterized by high levels. As example, for a four-stroke internal combustion engine with four cylinders, the fundamental period is twice the period of the rotation of the engine output shaft. Induced dynamic responses of every fixed gear driving the idle gears correspond to periodic functions with a rich spectral content. Then, $y(t)$ can be written as follows:

$$
y(t)=\sum_{k=1}^{\infty} H_{k} \cos \left(k \omega t-\varphi_{k}\right),
$$

where $\omega$ is the fundamental circular frequency, and $H_{k}$ and $\varphi_{k}$ are, respectively, amplitude and phase of the harmonic components of order $k$. A stationary regime is considered. Amplitude and phase are assumed to be independent of the rotational speed of the engine and the dynamic response of the entire driveline.

3.3. Impulse. Dimensionless impulse associated with impacts is introduced in order to characterize excitation forces transmitted to the gearbox.

As the impacts duration is assumed to be very short, the impulse can be expressed as follows:

$$
I=\lim _{\delta t \rightarrow 0}\{m(\dot{x}(t+\delta t)-\dot{x}(t))\} .
$$


3.4. Dimensionless Equations. Introducing dimensionless variables,

$$
\begin{gathered}
\tilde{x}=\frac{x}{H}, \quad \tilde{y}=\frac{y}{H}, \\
\tilde{j}=\frac{j}{H}, \quad \tilde{t}=\omega t, \\
\tilde{R}=\frac{R}{F} .
\end{gathered}
$$

The dimensionless number $\Lambda$ depends on the equivalent mass $m$, the constant force associated with the drag torque $F$, the amplitude of the excitation $H$, and the fundamental circular frequency $\omega$ :

$$
\Lambda=\frac{m H \omega^{2}}{F}
$$

Equations (1), (2), (4), and (5) can be returned as follows:

$$
\begin{gathered}
\Lambda \ddot{\tilde{x}}=-1, \quad \tilde{y}<\tilde{x}<\tilde{y}+\tilde{j}, \\
\dot{\tilde{x}}_{t+\delta t}-\dot{\tilde{y}}_{t+\delta t}=-r\left(\dot{\tilde{x}}_{t}-\dot{\tilde{y}}_{t}\right), \\
\widetilde{R}=1+\Lambda \ddot{\tilde{y}} .
\end{gathered}
$$

And the dimensionless impulse can be written as follows:

$$
\tilde{I}=\frac{I}{m \omega H_{1}}
$$

\section{Dynamics Induced by a Purely Harmonic Excitation}

Figure 2 displays dimensionless impulse versus parameter $\Lambda$ for an harmonic excitation. Five parts are observed and, so, five different dynamic responses of the idle gear. The part A corresponds to a permanent contact motion. The part $\mathrm{B}$ corresponds to periodic responses with impacts on the active flank followed by a permanent contact. The part C corresponds to a periodic response with one impact on the active flank per period. The part D corresponds to chaotic motion. Finally, the part E corresponds to the periodic response with two impacts per period, one on the active flank (positive impulses) and the other on the reverse one (negative impulses). The idle gear crosses the entire backlash. This kind of response exists for a large range of $\Lambda$.

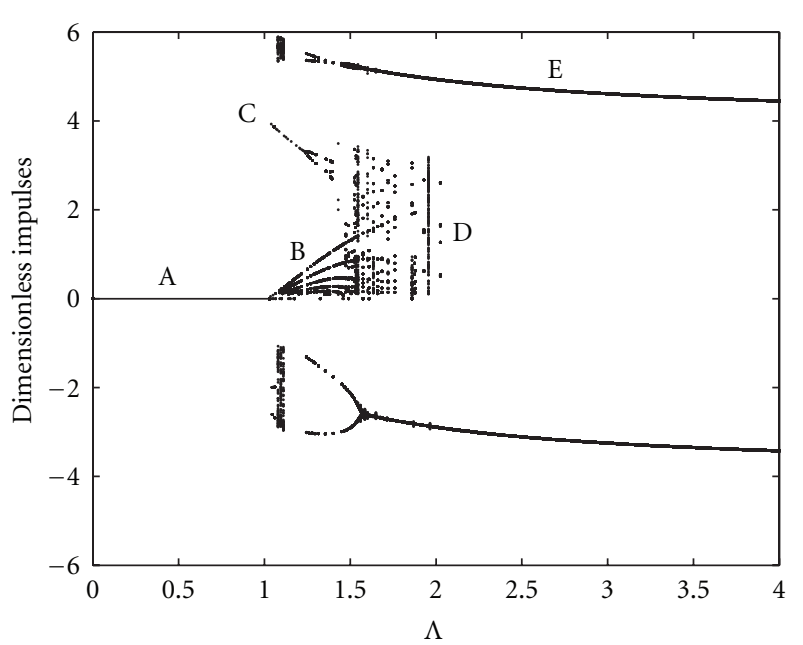

FIGURE 2: Impulses versus $\Lambda$ for an excitation purely harmonic, $r=$ 0.65 and $j=8$.

Dynamic response histories are displayed on Figure 3. They correspond to the different parts described on the dimensionless impulse map (except permanent contact motion).

\section{Effects of a Multiharmonics Excitation}

In this section, the second harmonic component is introduced, in order to impose an excitation more representative of the velocity fluctuation. The ratio of second harmonic $\mathrm{H}_{2}$ to first harmonic amplitude $\mathrm{H}_{1}$ is 0.25 and its phase $\varphi_{2}$ is equal to $45^{\circ}$. Compared to purely harmonic case shown in Figure 2, dynamic behavior is very different (see Figure 4). The parts C and E have disappeared. Beyond solutions corresponding to successions of permanent contact and impacts, chaotic responses solutions characterized by impacts on the active and reverse flanks are observed.

The phase of the second harmonic plays also a significant role. Figure 5 displays the dimensionless impulses versus $\Lambda$ for $\varphi_{2}$ equal to $90^{\circ}$. Periodic responses are observed. The large range of chaotic responses disappears. The effect of the phase on the dynamic response is highlighted on Figure 6 which displays the evolution of the dimensionless intensity versus phase for fixed parameter $\Lambda$.

Figure 7 displays the Poincaré map for $\Lambda$ equal to 3.3 (ratio of $\mathrm{H}_{2}$ to $\mathrm{H}_{1}$ is $0.25, \varphi_{2}$ is $45^{\circ}$ ). The strange attractor indicates that the idle gear response is chaotic. Time response history and corresponding Poincaré map are displayed on Figure 8 for the dynamic response corresponding to $\Lambda$ equal to 3.3 (ratio of $\mathrm{H}_{2}$ to $\mathrm{H}_{1}$ is $0.25, \varphi_{2}$ is $90^{\circ}$ ). The dynamic response of the idle gear is periodic with two impacts per period, one impact on the active flank and the other on the reverse flank, as observed for a purely harmonic excitation with the same value $\Lambda$ (Figure 3 ).

Finally, frequency contents and phases of the excitation source play a significant role on the dynamic of the idle gear. Various kinds of responses are observed, from periodic ones with impacts on the active and reverse flanks to chaos. 


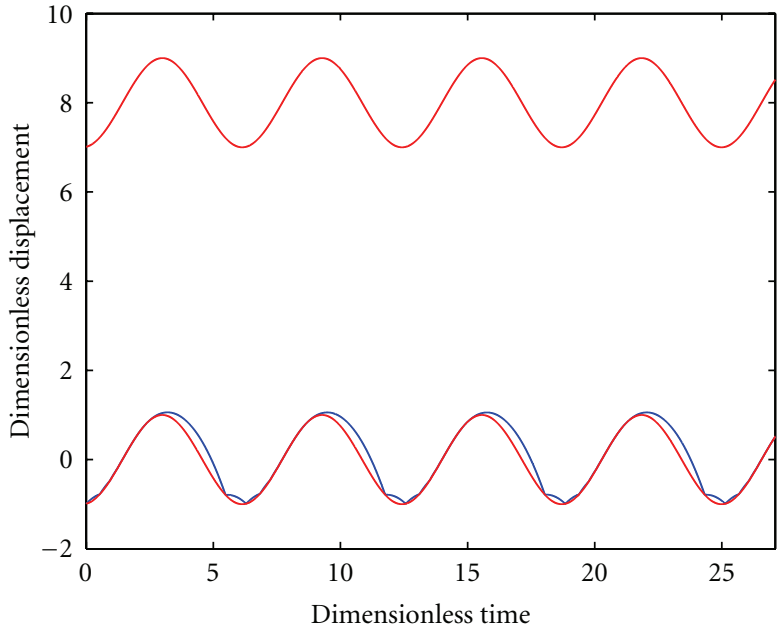

(a) 3 impacts and permanent contact phase

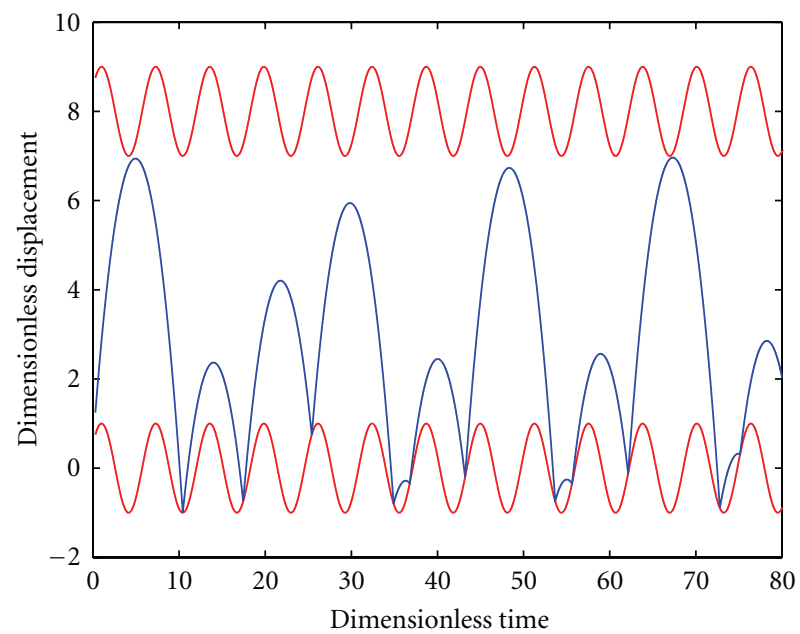

(c) Chaotic response

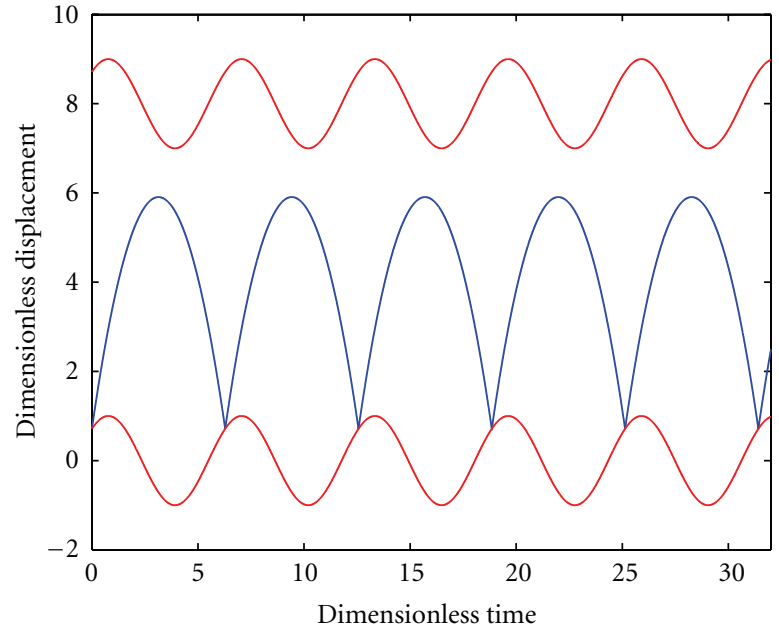

(b) Periodic response with one impact per period

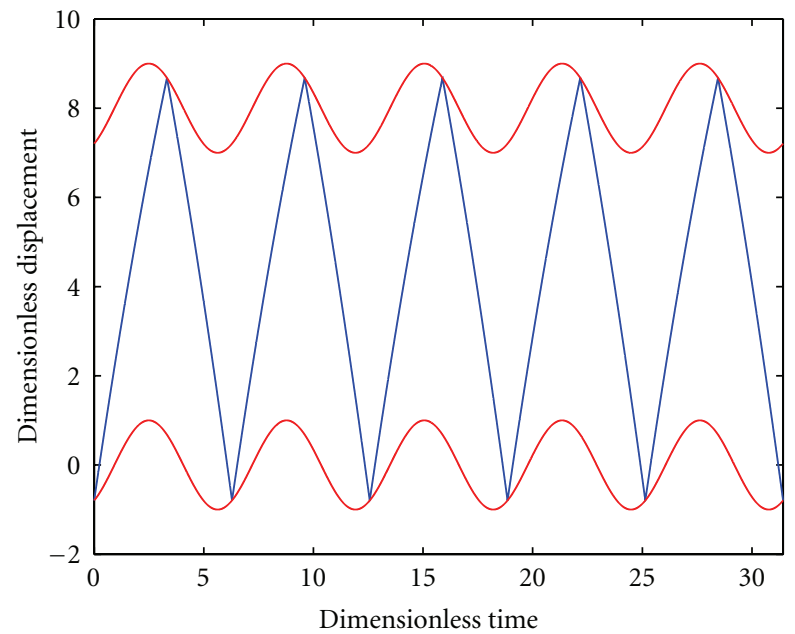

(d) Periodic response with two impacts per period

Figure 3: Time response histories of the idle gear for $r=0.65$ and $j=8$. Upper and lower sinusoidal curves correspond to the motion of the driving gear teeth separated by constant clearance.

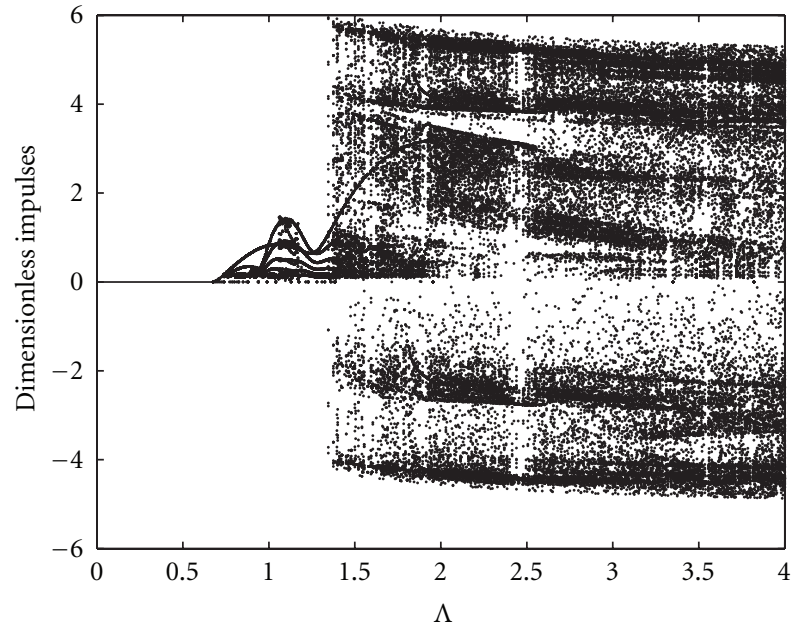

FIGURE 4: Impulses versus $\Lambda$ for a multiharmonics excitation $\varphi_{2}=$ $45^{\circ}, r=0.65$, and $j=8$.

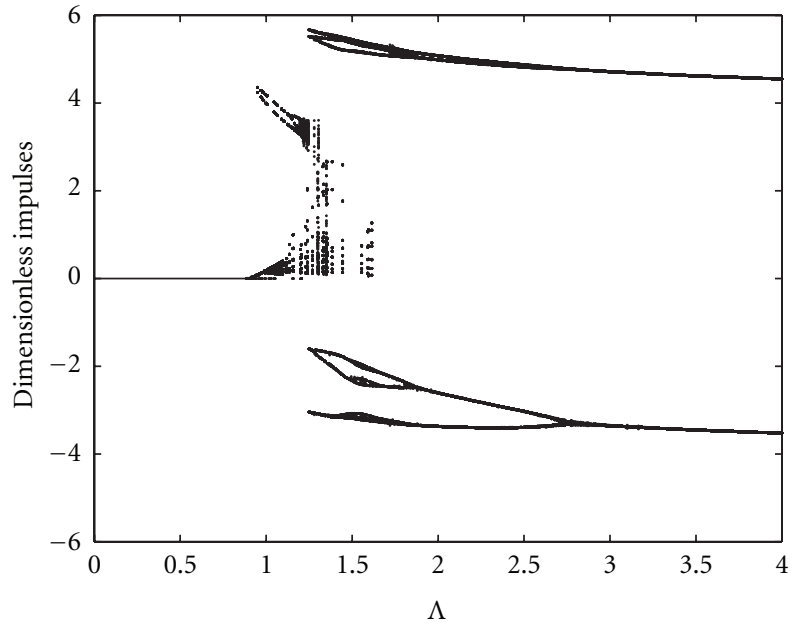

Figure 5: Impulses versus $\Lambda$ for a multiharmonics excitation $\varphi_{2}=$ $90^{\circ}, r=0.65$, and $j=8$. 


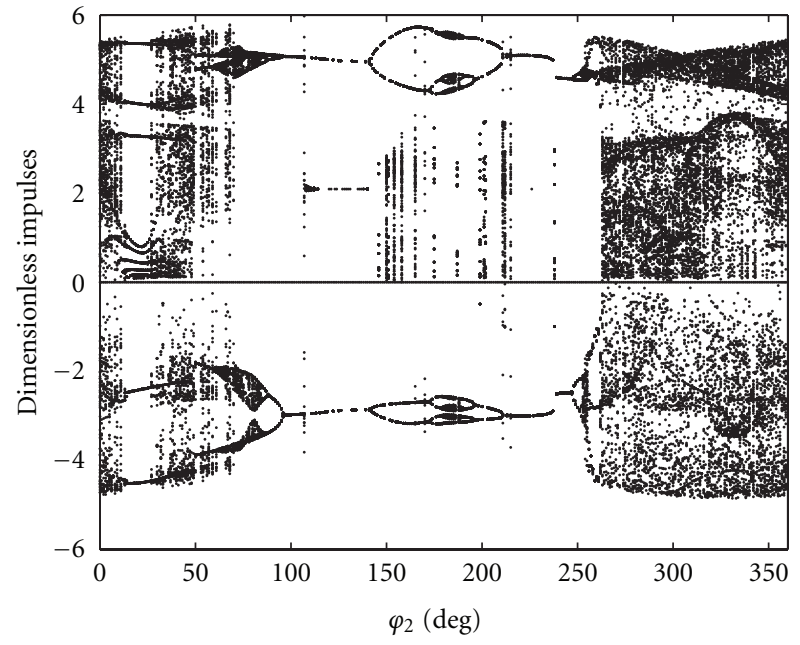

FIgURE 6: Impulses versus $\varphi_{2}$ for $\Lambda=1.95, r=0.65$, and $j=8$.

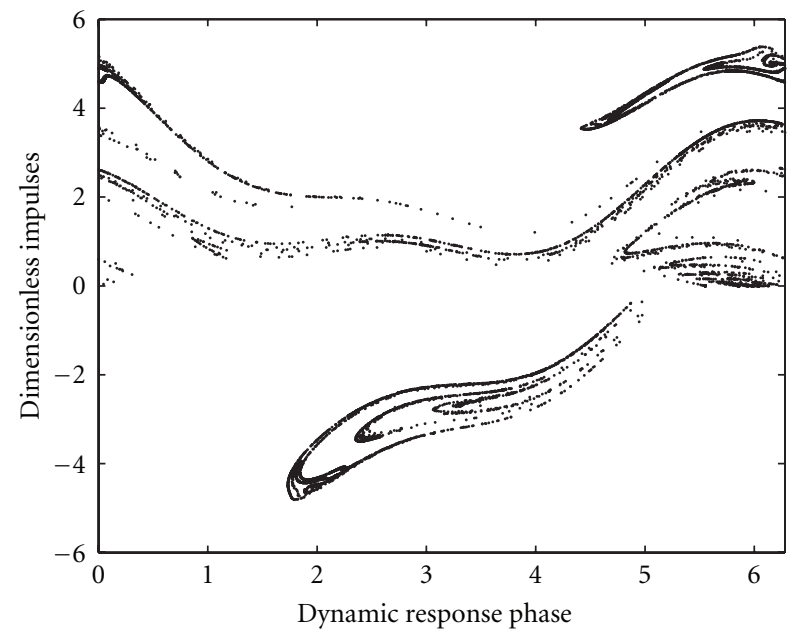

FIgURe 7: Poincaré map for a multiharmonics excitation $\varphi_{2}=45^{\circ}$ for $\Lambda=3.3, r=0.65$, and $j=8$.

\section{Conclusion}

Noise and vibration due to gear rattle are an irritating problem. In this paper, a nonlinear single-degree-of-freedom system modeling the idle gear dynamics has been built. Some effects of a multiharmonics excitation are analyzed. Dynamic responses are compared to the ones obtained in the case of a purely harmonic excitation. Results show that, for usual amplitudes of the second harmonic of excitation, significant modifications of responses are observed, including emergence or extinction of chaotic motions. Further, we show that phases play an important role on the dynamic of the idle gear. We can conclude that controlling the rattle noise requires the precise knowledge of the excitation source corresponding to the driving fixed gear response spectral content. Finally, the variety of responses (periodic, chaotic responses, impact occurrences on reverse and active flanks, etc.) play an important effect on the resulting noise emitted from the gearbox, and more particularly on its sound quality.

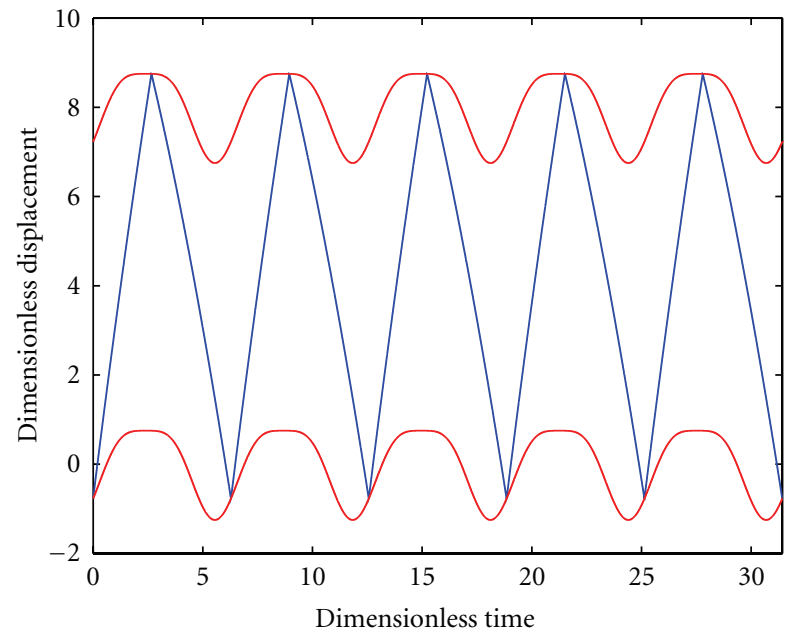

(a)

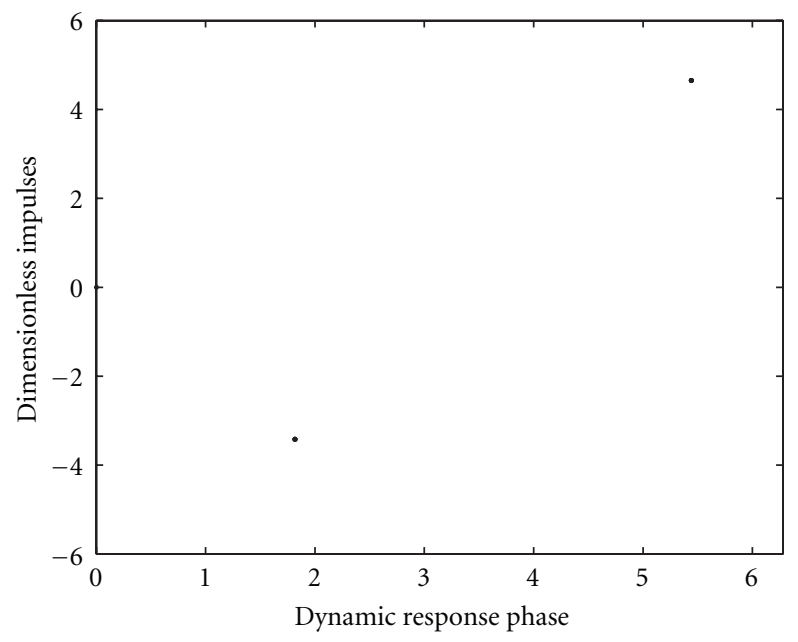

(b)

Figure 8: Time response history (a) and Poincaré map (b) for a multiharmonics excitation $\varphi_{2}=90^{\circ}$ for $\Lambda=3.3, r=0.65$, and $j=8$.

\section{Acknowledgments}

The authors acknowledge Renault S.A.S. for the support of a research grant and the French Research Agency for its financial support (project ANR-06-BLAN-0115).

\section{References}

[1] M. A. Trapp and K. K. Hodgdon, "An evaluation of friction and impact induced acoustic behaviour of selected automotive materials, part II: impact induced acoustics," International Journal of Vehicle Noise and Vibration, vol. 4, no. 1, pp. 17-34, 2008.

[2] M. S. Qatu, M. K. Abdelhamid, J. Pang, and G. Sheng, "Overview of automotive noise and vibration," International Journal of Vehicle Noise and Vibration, vol. 5, no. 1-2, pp. 1-35, 2009.

[3] A. Rust, F. K. Brandl, and G. E. Thien, "Investigations into gear rattle phenomena-key parameters and their influence 
on gearbox noise," Institution of Mechanical Engineers, pp. 113-120, C404/001, 1990.

[4] T. Sakai, Y. Doi, K. Yamamoto, T. Ogasawara, and M. Narita, "Theoretical and experimental analysis of rattling noise of automotive gearbox," Tech. Rep. 810773, pp. 85-91, Society of Automotive Engineers, 1981.

[5] R. Singh, H. Xie, and R.-J. Comparin, "Analysis of automotive neutral grear rattle," Journal of Sound and Vibration, vol. 131, no. 2, pp. 177-196, 1989.

[6] C. Padmanabhan and R. Singh, "Influence of clutch design on the reduction and perception of automotive transmission rattle noise," in Proceedings of the National Conference on Noise Control Engineering: Noise Control in Aeroacoustics, Williamsburg, Va, USA, 1993.

[7] F. Pfeiffer, "Modelling problems of rattling in gear-boxes," in Proceedings of the MPT'91, Japan Society of Mechanical Engineers International Conference on Motion and Power Transmission, pp. 43-48, Hiroshima, Japan, November 1991.

[8] G. Weidmer and G. Lechner, "Rattling vibrations in automotive transmissions," in Proceedings of the MPT'91, Japan Society of Mechanical Engineers International Conference on Motion and Power Transmission, pp. 37-42, Hiroshima, Japan, November 1991.

[9] J. Wang, M. Qatu, and R. Dukkipati, "A metric for automotive transaxle rattle," International Journal of Vehicle Noise and Vibration, vol. 5, no. 4, pp. 300-307, 2009.

[10] J. Perret-Liaudet and E. Rigaud, "Some effects of gear eccentricities on automotive rattle noise," in Proceedings of the 10th ASME International Power Transmission and Gearing Conference, no. 34794, p. 9, Las Vegas, Nev, USA, September 2007.

[11] J. Perret-Liaudet, Y. Kadmiri, and E. Rigaud, "Automotive rattle noise: some theoretical results associated with the restitution coefficient law modelling teeth impacts," in Proceedings of the Japan Society of Mechanical Engineers International Conference on Motion and Power Transmission, Japan, May 2009.

[12] Y. Kadmiri, J. Perret-Liaudet, and E. Rigaud, "Experimental study of rattle noise in automotive gearboxes," in Proceedings of the VDI International conference on Gears, Munich, Germany, October 2010.

[13] S. N. Dogan, J. Ryborz, and B. Bertsche, "Rattling and clattering noise in automotive transmissions - simulation of drag torque and noise," in Transient Processes in Tribology, G. Dalmaz et al., Ed., pp. 109-119, Elsevier, New York, NY, USA, 2004.

[14] M. Barthod, B. Hayne, J. L. Tébec, and J. C. Pin, "Experimental study of dynamic and noise produced by a gearing excited by a multi-harmonic excitation," Applied Acoustics, vol. 68, no. 9, pp. 982-1002, 2007.

[15] M. Barthod and J. L. Tebec, "Auditory perception of noise known as rattle in gearboxes," Acta Acustica, vol. 91, no. 1, pp. 180-191, 2005.

[16] L. Irimescu, I. Musca, and S. Alaci, "Aspects theoriques et expérimentaux concernant le coefficient de restitution," The annals of university "Dunarea De Jos" of Galati, fascicle VIII, ISSN 1221-4590, Tribilogy. 

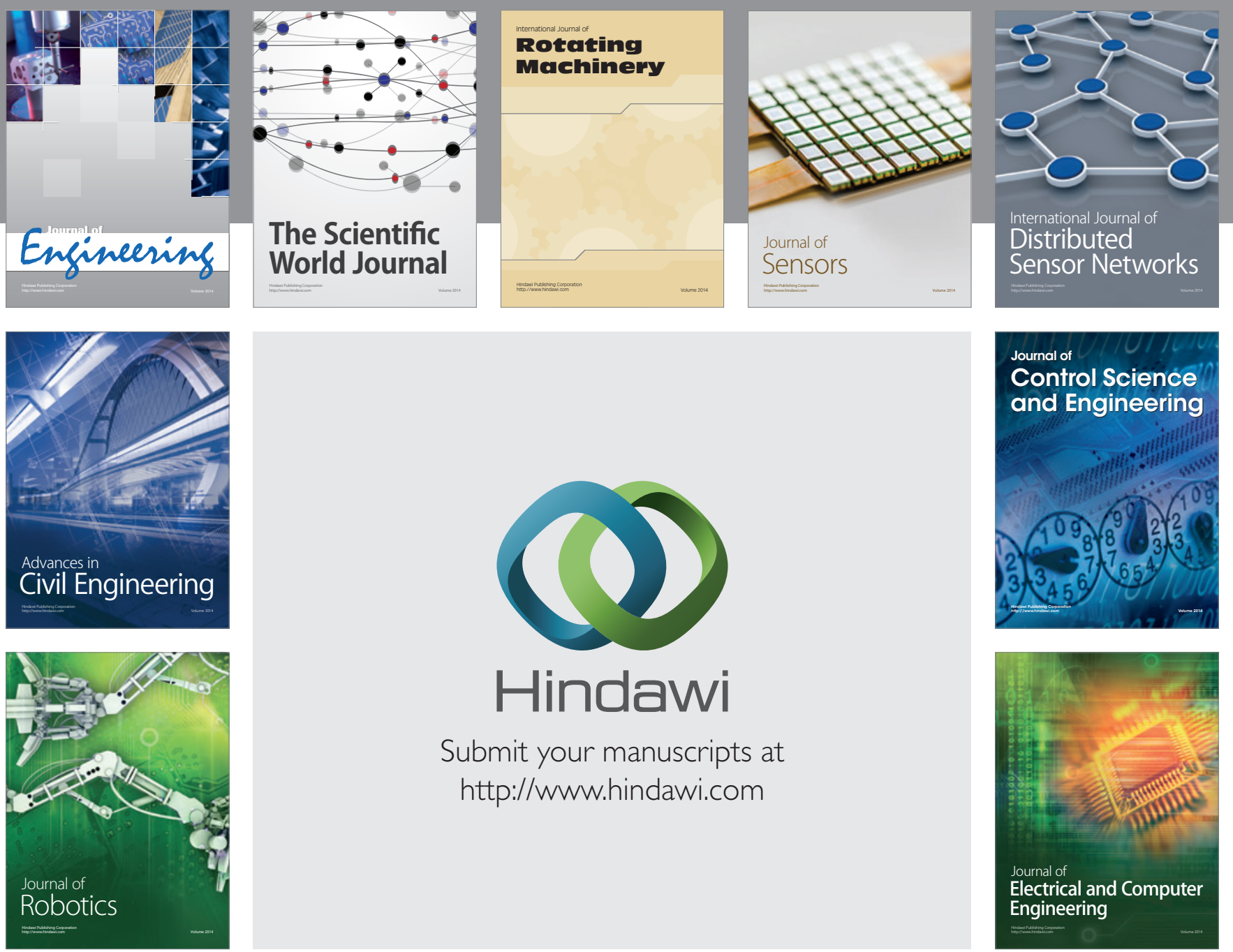

Submit your manuscripts at

http://www.hindawi.com
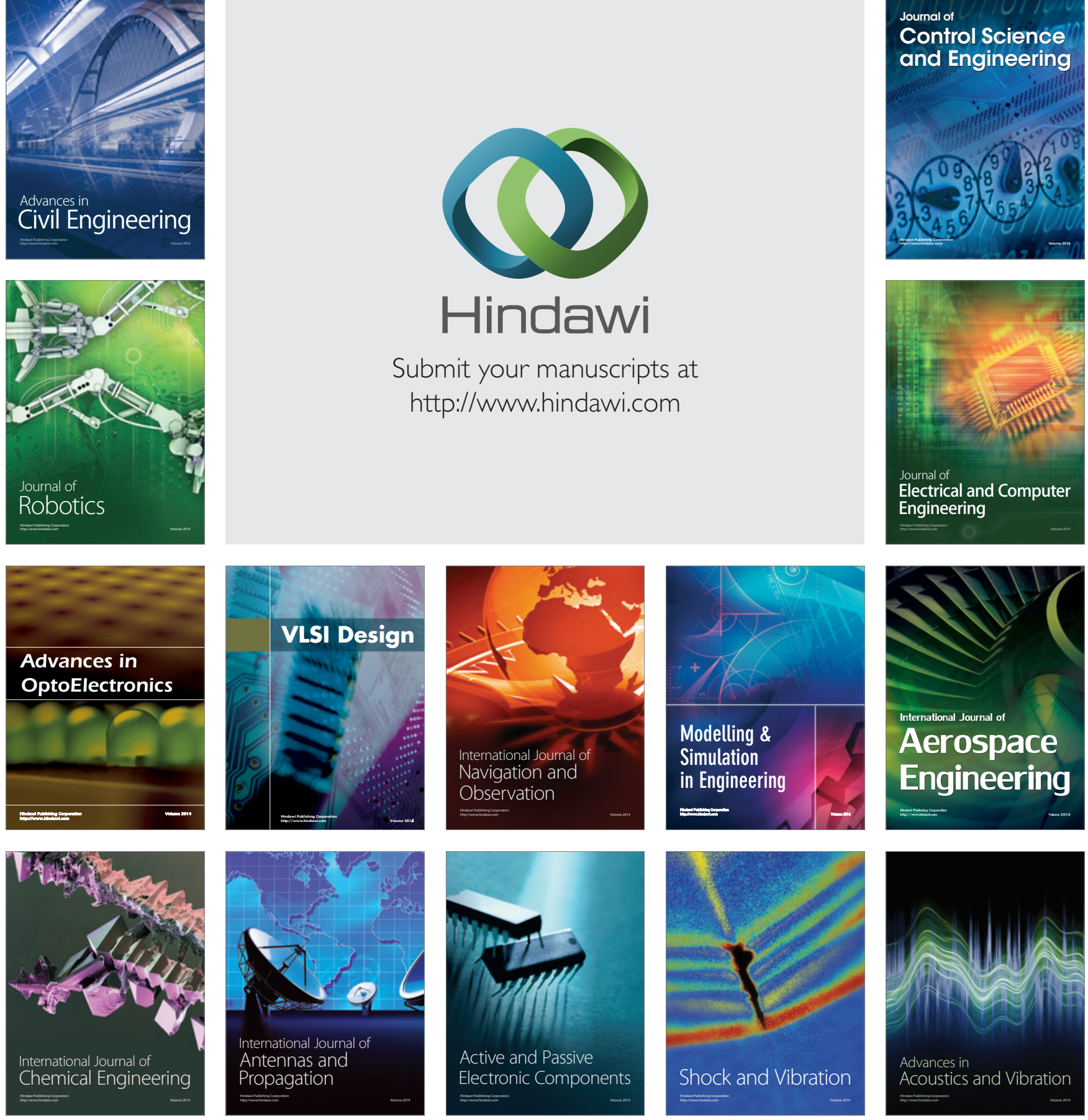